\title{
Mecanismo celular y molecular de la adicción a benzodiacepinas
}

\author{
Itzel Rosas-Gutiérrez, ${ }^{1}$ Karina Simón-Arceo, ${ }^{2}$ Francisco Mercado ${ }^{2}$
}

Actualización por temas

\section{SUMMARY}

Benzodiazepines (BZD) are a group of psychiatric drugs widely prescribed since their introduction in the clinical practice in the early 60's. These drugs have a high therapeutic efficacy in the anxiety treatment. The pharmacological action of BZD at molecular level over the Central Nervous System is very well established. However, there has always been a strong concern from different health systems about the addictive effects that the BZD may cause. The aim of this article is to give a precise description about the BZD molecular mechanism of addiction that has been resolved in recent time, based on results obtained in basic research, as well provide information about the epidemiological impact of the medical use of the BZD over the population.

Key words: Benzodiazepines, addiction, abuse drugs, mechanism of action, epidemiology.

\section{RESUMEN}

Las benzodiacepinas (BZD) son un grupo de psicofármacos ampliamente prescritos desde su introducción en la práctica clínica a principios de los años 1960. Estos fármacos cuentan con una alta eficacia terapéutica en el tratamiento de la ansiedad. Su mecanismo de acción sobre el Sistema Nervioso Central a nivel molecular es bien conocido, sin embargo siempre ha existido preocupación entre distintos sistemas de salud por los efectos de adicción farmacológica que provocan. El objetivo de este trabajo es abordar los resultados obtenidos recientemente en investigación básica y describir el mecanismo por el cual las benzodiacepinas producen sus efectos adictivos a nivel molecular, así como informar sobre el impacto epidemiológico que tiene su uso.

Palabras clave: Benzodiacepinas, adicción, drogas de abuso, mecanismo de acción, epidemiología.

\section{INTRODUCCIÓN}

Fue en 1930 cuando Leo Sternback descubrió las benzodiacepinas (BZD), pero hasta el año de 1957 se introdujo a la práctica clínica el uso del clordiacepóxido (benzodiacepina ansiolítica). ${ }^{1}$ A partir de 1963, con la introducción del diacepam (Valium) las BZD se utilizarón a gran escala gracias al incremento del margen de seguridad y eficacia terapéutica respecto de las sustancias empleadas hasta entonces como ansiolíticos, lo que condujo rápidamente al remplazo de los barbitúricos. ${ }^{2}$

Así, actualmente las BZD conforman el grupo de fármacos más utilizado para el tratamiento de la ansiedad. Se utilizan más de 15 tipos de éstos para el tratamiento de una amplia variedad de malestares psicológicos y físicos, ya que generan menos efectos secundarios que los barbitúricos, son relativamente seguras en el caso de sobredosis y tienen menor riesgo de generar dependencia. ${ }^{2}$
Adicionalmente a su acción ansiolítica, y debido a que reducen la excitabilidad neuronal, a las BZD se les han dado otras aplicaciones en la práctica clínica como: anticonvulsivos, relajantes musculares e inductores del sueño. ${ }^{1}$

Desde hace algunos años determinadas asociaciones públicas han expresado su preocupación sobre la posible prescripción excesiva de este grupo de fármacos y los psiquiatras, a su vez, han advertido sobre el riesgo que tienen para producir efectos secundarios graves, así como producir dependencia farmacológica (sobre todo las BZD con una potencia alta y vida media corta). Después de esto, si bien ha disminuido el número de prescripciones para el uso a corto plazo de la ansiedad, su amplio uso en el tratamiento a largo plazo del insomnio, continua, y sigue siendo uno de los grupos farmacológicos más prescritos como se detalla a continuación. ${ }^{3}$

Departamento de Ciencias de la Salud, Universidad Popular Autónoma del Estado de Puebla.

2 Dirección de Investigaciones en Neurociencias, Instituto Nacional de Psiquiatría Ramón de la Fuente Muñiz.

Correspondencia: Dr. Francisco Mercado. Dirección de Investigaciones en Neurociencias, Instituto Nacional de Psiquiatría Ramón de la Fuente Muñiz. Calz. México-Xochimilco 101, San Lorenzo Huipulco, Tlalpan, 14370, México DF. Tel. +52 (55) 41605105 . Fax +52 (55) 5655 9980. E-mail: fmercado@imp.edu.mx; mercado.aca@gmail.com

Recibido: 2 de octubre de 2012. Aceptado: 19 de diciembre de 2012. 


\section{EPIDEMIOLOGÍA DE ADICCIÓN A LAS BENZODIACEPINAS}

La OMS establece que el uso adecuado de medicamentos significa que los pacientes reciban fármacos apropiados para sus necesidades clínicas, a dosis ajustadas a su situación particular, durante un periodo de tiempo adecuado y al mínimo costo posible para ellos y para la comunidad. El uso clínicamente inapropiado o económicamente ineficiente de los medicamentos supone un problema muy grave a nivel mundial: se estima que más de la mitad de todos los fármacos se prescriben, dispensan o venden de forma inapropiada. Si a esta situación se suma el potencial adictivo de algunos de ellos, el problema se complica y puede agravarse. ${ }^{4}$

El uso y prescripción de las BZD se ha relacionado con un alto riesgo de abuso y dependencia debido a su manejo inadecuado ya que, aun administradas regularmente a niveles terapéuticos, poseen un potencial de dependencia mayor que otros fármacos de acción ansiolítica. Asimismo, se ha reportado tolerancia farmacológica cuando la prescripción es por un tiempo mayor a las cuatro semanas, así como la aparición del síndrome de abstinencia en el 30\% de los pacientes después de un tratamiento de ocho semanas de duración. ${ }^{5-7}$

Aunque los datos sobre la prevalencia de su consumo muestran variabilidad entre los países, en general reflejan una tasa elevada de consumo. Por ejemplo, en el último año, en los países occidentales, entre 10 y $20 \%$ de la población reconoce el consumo de BZD y entre 1 y $3 \%$ las ha consumido diariamente por más de un año. ${ }^{8}$ En España, durante el 2006, se reportaron datos del Sistema Nacional de Salud que reflejan prescripciones por un total de 69.9 DHD (dosis diarias definidas por cada 1000 habitantes-día), el doble que en el año 1993. En el 2010 significó que aproximadamente entre 6 y 7\% de su población estaba en tratamiento con BZD. ${ }^{9}$ En México, los datos reportados en la última Encuesta Nacional de Adicciones señalan a las BZD como los fármacos de prescripción más usados en hombres y mujeres de 12 a 65 años de edad. ${ }^{6} \mathrm{~A}$ pesar de los reportes en distintos países en cuanto a la prevalencia de su uso, los números van en aumento y se observa dificultad para disminuirlos. ${ }^{9}$

En cuanto a las variables y factores de riesgo para el desarrollo de dependencia, hay tres que tienen una influencia crucial: 1. la naturaleza del fármaco, 2. el individuo mismo y 3. el medio ambiente. ${ }^{10}$

Dentro de los factores relacionados con la naturaleza del fármaco, la cinética de las BZD ha demostrado ser un elemento que influye sobre su abuso. Las BZD con mayor lipofilia, y por lo tanto con mayor absorción, tienen más probabilidad de producir este efecto, en comparación con las que se absorben más lentamente. Por ejemplo, en países europeos el flunitrazepam, de alta lipofilia, es la BZD reportada con mayor abuso mientras que en los Estados Unidos es el diacepam. ${ }^{10}$

La genética del individuo es un elemento que también tiene influencia sobre su abuso. ${ }^{10,11} \mathrm{El}$ midazolam, por ejem- plo, es una BZD que se metaboliza exclusivamente a través de la familia de enzimas CYP3A, que forma parte de la familia del citocromo P-450, y a pesar de ser una enzima no polimórfica su actividad varía de forma considerable entre los individuos. ${ }^{12}$ En el caso del diacepam y el flunitrazepam, la mayor parte de su metabolismo se realiza por medio de la enzima CYP2C19 (40\% o más). Entre 17 y 20\% de los individuos asiáticos son metabolizadores lentos de CYP2C19, lo que significa que aproximadamente 250 millones de personas no metabolizan adecuadamente estos fármacos. ${ }^{10}$

La edad también influye en el uso de sustancias adictivas. Cuando se trata del consumo de BZD, estudios realizados en diversos países y en diferentes estratos sociales revelan que las personas de mayor edad las consumen más que las personas jóvenes, esto debido a una mayor prevalencia de insomnio en la edad madura. ${ }^{10}$ Un estudio realizado en la comunidad de Valencia, en España, mostró que entre 14 y $25 \%$ de ancianos en tratamiento reciben una prescripción inadecuada, en la que destaca el mal uso de BZD de vida media larga como el dipiridamol, y de otros fármacos como la amitriptilina y la clorpropamida, provocando una potenciación de los efectos adversos y mayor riesgo de interacciones medicamentosas. ${ }^{13}$

En general, los hombres superan a las mujeres en el consumo de drogas legales e ilegales, excepto en el caso de las BZD. Las mujeres de entre 35 y 64 años son las que más recurren a ellas. Asimismo, al estar las mujeres expuestas a diferentes niveles de progesterona desde la pubertad hasta la menopausia, son más sensibles a las consecuencias negativas del uso de las BZD. Se ha demostrado que los niveles de progesterona potencian el efecto de las BZD y favorecen su uso y abuso entre ellas. ${ }^{14,15} \mathrm{El}$ alcohol, un factor externo, ejerce también una influencia sobre el abuso de las BZD debido a que potencia su efecto farmacológico por que actúan sobre los mismos receptores. Se ha reportado que entre $15 \mathrm{y}$ $20 \%$ de los pacientes alcohólicos en tratamiento presentan un abuso a estos fármacos; muchos de ellos las han tomado como automedicación para el tratamiento de los síntomas de abstinencia o ansiedad, como euforizantes o bien (como ya se mencionó), para potenciar los efectos del alcohol mismo. ${ }^{16}$

Es así que en la actualidad es indispensable el buen uso y la prescripción racional de estos fármacos. ${ }^{17}$ En las últimas décadas se han realizado avances muy importantes en el conocimiento de las bases neurobiológicas de las adicciones, y esto ha permitido cambiar la conceptualización de este trastorno que evolucionó, de ser considerado un vicio a enfocarlo como un trastorno psico-orgánico que requiere de un tratamiento especializado. ${ }^{18}$

\section{MECANISMO DE ACCIÓN DE LAS BZD}

El ácido $\gamma$-aminobutírico (GABA) es el principal neurotransmisor inhibitorio del Sistema Nervioso Central de los 
mamíferos. El GABA puede activar dos tipos de receptores, uno metabotrópico $\left(\mathrm{GABA}_{\mathrm{B}}\right)$, acoplado a una proteína $\mathrm{G}$ con función presináptica y postsináptica, y uno ionotrópico $\left(\mathrm{GABA}_{\mathrm{A}}\right)$ con función sináptica localizado en la membrana postsináptica. ${ }^{19,20}$

El receptor $\mathrm{GABA}_{\mathrm{A}}$ es el receptor inhibitorio acoplado a un canal iónico más abundante en el Sistema Nervioso Central, su poro conductor es selectivo para iones $\mathrm{Cl}^{-19,20} \mathrm{y}$ es modulado alostéricamente por diferentes fármacos como las BZD, los barbitúricos y también por el etanol. Este receptor es una glicoproteína heteropentamérica formada por la combinación de múltiples subunidades polipeptídicas. ${ }^{19}$

Se conocen siete clases de subunidades formadoras de poro $(\alpha, \beta, \gamma, \delta, \varepsilon, \theta$ y $\rho)$ y diversas isoformas para cada clase. A la fecha se han identificado 18 subunidades. Sin embargo, la estequiometría más frecuente de los receptores es cuando se encuentran formados por dos subunidades $\alpha$, dos $\beta$ y una $\gamma \cdot{ }^{19}$

El sitio de unión específico a las BZD en el receptor GA$\mathrm{BA}_{\mathrm{A}}$ es llamado sitio de unión benzodiacepínico, y está constituido de manera principal por el aminoácido histidina en la posición 101 de la subunidad $\alpha 1$ y en sitios homólogos de las demás subunidades $\alpha 1{ }^{19}$ La substitución de este aminoácido por algún otro en esta posición evita el efecto farmacológico de las BZD. Los ligandos de estos sitios no están limitados a los fármacos de estructuras benzodiacepínicas. Otros fármacos como el zolpidem y la zopliclona se unen también a este sitio benzodiacepínico. El mecanismo de activación del receptor $\mathrm{GABA}_{\mathrm{A}^{\prime}}$ tanto por benzodiacepinas como por no benzodiacepinas, aparentemente es el mismo. ${ }^{19,20}$

El acoplamiento de las BZD a su sitio de unión en el receptor $\mathrm{GABA}_{\mathrm{A}}$ genera un incremento en la frecuencia de apertura del canal iónico con respecto a cuando el receptor $\mathrm{GABA}_{\mathrm{A}}$ se encuentra sólo en presencia del neurotransmisor GABA. En otras palabras, las BZD potencian el efecto del neurotransmisor GABA sobre sus receptores ionotrópicos, lo que permite una mayor entrada del ión cloro a las neuronas favoreciendo la hiperpolarización de su potencial de membrana; la neurona se vuelve menos susceptible a los estímulos activadores (menos excitable) y se produce un estado de inhibición neuronal. ${ }^{19}$

El efecto de las BZD sobre el receptor $\mathrm{GABA}_{\mathrm{A}}$ se conoce como modulación alostérica ya que modifica la disposición tridimensional del receptor, potenciando así el efecto de apertura del canal de $\mathrm{Cl}^{-}$por la acción del GABA. ${ }^{21}$

La acción farmacológica que llevan a cabo las BZD depende del tipo de subunidad $\alpha$ que contenga el receptor $\mathrm{GABA}_{\mathrm{A}}$. El sitio receptor a benzodiacepinas de la subunidad $\alpha 1$ es el más abundante en el Sistema Nervioso Central, y regula las acciones anticonvulsivas, hipnóticas y sedantes de las BZD; esta subunidad se expresa principalmente en las cortezas del cerebro y del cerebelo. El sitio receptor a BZD de la subunidad $\alpha 2$ regula las acciones ansiolíticas y su expresión predomina en la amígdala del lóbulo temporal (particularmente en el núcleo central), el hipocampo y el cuerpo estriado. El sitio benzodiacepínico de la subunidad $\alpha 3$ se conoce también como receptor periférico, la acción farmacológica de las BZD sobre esta subunidad está relacionada con el efecto relajante muscular. La localización de las subunidades $\alpha 1, \alpha 2$ y $\alpha 3$ son principalmente sinápticas, mientras que la subunidad $\alpha 5$ (relacionada también con el efecto relajante muscular) tiene una localización predominantemente extrasináptica. ${ }^{19,22}$

Los receptores $\mathrm{GABA}_{\mathrm{A}}$ que contienen subunidades $\alpha 1$, $\alpha 2$, $\alpha 3$ y $\alpha 5$, en combinación con las subunidades $\beta$ y $\gamma$, se unen a las BZD clásicas, como por ejemplo el diacepam, mientras que los receptores $\mathrm{GABA}_{\mathrm{A}}$ que contienen subunidades $\alpha 4$ y $\alpha 6$ no se unen a las BZD clásicas. Esencialmente todas las BZD que están indicadas para uso clínico se unen al receptor GABA $\mathrm{A}_{\mathrm{A}}$ que contiene subunidades $\alpha 1, \alpha 2, \alpha 3$ y $\alpha 5$. El zolpidem, mencionado anteriormente, es el único fármaco con indicación clínica que tiene selectividad específica: tiene alta afinidad por el receptor $\mathrm{GABA}_{\mathrm{A}}$ con subunidad $\alpha 1$, afinidad media para el receptor $\mathrm{GABA}_{\mathrm{A}}$ con subunidades $\alpha 2$ o $\alpha 3$ y no tiene afinidad para el receptor GABA $_{\mathrm{A}}$ con subunidad $\alpha 5 .^{20,23}$

\section{MECANISMO GENERAL DE ADICCIÓN A LAS SUSTANCIAS DE ABUSO}

La dependencia a ciertas sustancias y fármacos se debe a una disfunción neurobiológica de estructuras cerebrales mesencefálicas, límbicas y corticales y de circuitos cerebrales que están implicados en la motivación y los procesos de reforzamiento de la conducta. ${ }^{16}$

Las sustancias que causan adicción (como la cocaína, los opioides o la nicotina), aumentan de forma indirecta la liberación o concentración de dopamina (DA) en el núcleo accumbens (NAC). El núcleo que libera DA al NAC es el área ventral tegmental (AVT), que se localiza en el mesencéfalo, y que no sólo inerva al NAC sino también a un gran número de regiones del encéfalo. ${ }^{24}$

Tanto el AVT como el NAC son regiones del cerebro que están relacionadas con las vías de recompensa y aprendizaje. ${ }^{25}$ Es decir, estas sustancias adictivas actúan de forma similar a las recompensas naturales que causan normalmente gratificación o placer como las conductas necesarias para la conservación de la especie, por ejemplo el comer, la conducta sexual y las relaciones sociales. ${ }^{16}$ El estímulo crea un refuerzo en el consumo de dichas drogas y la exposición repetida de este estímulo se transforma en dependencia física. ${ }^{26}$

A nivel de las redes neuronales, las drogas de abuso incrementan la concentración de DA en el NAC por medio de tres mecanismos diferentes. Uno es el producido por drogas como las anfetaminas y la cocaína, en el cual la DA liberada al NAC se mantiene por más tiempo en el espacio sináptico debido a la inhibición de la recaptura de este neurotransmisor. ${ }^{27}$ 
Otro, en el cual la droga activa directamente a la neurona dopaminérgica y ésta libera una mayor cantidad de DA al NAC. Es el mecanismo que emplea la nicotina, la cual activa a receptores a acetilcolina expresados en las neuronas dopaminérgicas del AVT. ${ }^{27,28}$

En un tercer mecanismo, llamado desinhibición, se ve aumentada de forma descontrolada la liberación de DA por parte del AVT hacia el NAC debido a que se pierde el control inhibitorio que tienen las neuronas dopaminérgicas del AVT por parte de interneuronas GABAérgicas del mismo núcleo. Como ejemplo de drogas que producen desinhibición tenemos a los opioides y los canabinoides cuyos blancos farmacológicos, el receptor $\mu$-opioide y el receptor CB1, son expresados predominantemente por las interneuronas GABAérgicas, los cuales, una vez activados, reprimen la actividad eléctrica de estas últimas, liberándolas del control inhibitorio (deshinibición) que ejercen sobre las neuronas dopaminérgicas, lo que resulta en una mayor liberación de DA en le NAC ${ }^{27}$ (figura 1).

\section{MECANISMO NEUROBIOLÓGICO DE LA ADICCIÓN A LAS BZD}

Recientemente, Kelly Tan et al., de la Universidad de Ginebra, en Suiza, demostraron la similitud del mecanismo de adicción a las BZD con respecto a otras drogas adictivas. ${ }^{26}$

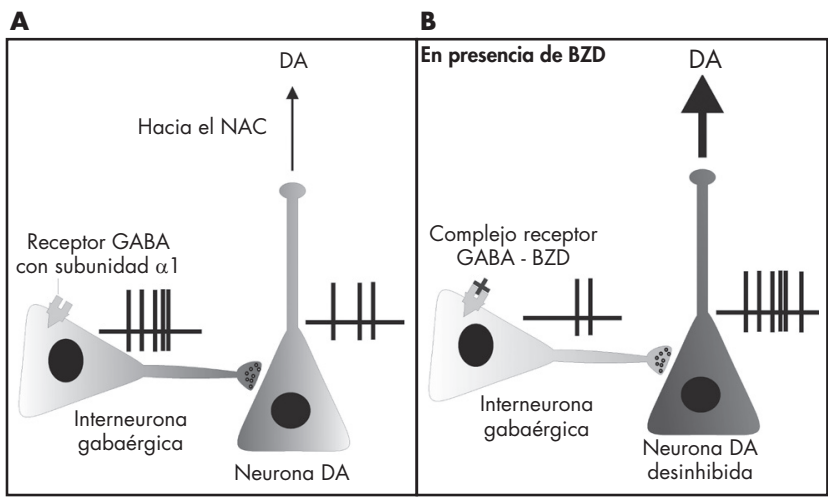

Figura 1. Esquema del mecanismo propuesto para la generación de dependencia física y adicción a las benzodiacepinas (BZD). En (A) se muestran dos neuronas del AVT: la interneurona inhibitoria (izquierda) hace contacto sináptico sobre la neurona dopaminérgica (ilustrada a la derecha). En los insertos se ejemplifica una frecuencia de disparo putativa para ambas neuronas. La neurona dopaminérgica proyecta al núcleo accumbens y libera en esa región su neurotransmisor: la dopamina (DA). La cantidad de DA que se libera al núcleo accumbens depende de la actividad de la neurona dopaminérgica, que a su vez depende de la actividad de la interneurona inhibitoria. En (B) se ilustra lo que se supone que sucede cuando se administra la BZD. Ésta se une al receptor $G_{A B A}$ en la interneurona inhibitoria que contiene la proteína $\alpha-1$. Esto resulta en un decremento de la inhibición hacia la neurona dopaminérgica, lo que aumenta su frecuencia de disparo. El resultado final es una mayor liberación de DA en el núcleo accumbens por el decremento en la inhibición, lo que refuerza el consumo de las BZD y genera tanto la adicción como la dependencia física (modificada de Mercado et al. 26).
Para una mejor comprensión de este mecanismo es necesario entender que el AVT es un núcleo cuya población neuronal está compuesta de la siguiente forma: 70\% de neuronas dopaminérgicas, $15 \%$ de interneuronas gabaérgicas y $15 \%$ de neuronas glutamatérgicas. ${ }^{2,27}$ La función de las interneuronas es reducir la actividad eléctrica de las neuronas dopaminérgicas, así, la cantidad de DA que se libera al NAC se encuentra bajo el control de la liberación del neurotransmisor GABA por parte de las interneuronas. ${ }^{26}$

Un importante hallazgo fue que aunque todas las neuronas del AVT expresan el receptor $\mathrm{GABA}_{\mathrm{A}^{\prime}}$ éste es distinto en su composición molecular entre las neuronas dopaminérgicas y las interneuronas gabaérgicas. La subunidad $\alpha$ del receptor $\mathrm{GABA}_{\mathrm{A}}$ de las neuronas dopaminérgicas del AVT es principalmente $\alpha 3$, mientras que en las interneuronas es $\alpha 1{ }^{26}$

Con base en esto fue posible determinar que el efecto de las BZD sobre el circuito AVT-NAC está determinado principalmente por su efecto sobre la subunidad $\alpha 1$ de los receptores $\mathrm{GABA}_{\mathrm{A}}$ que expresan las interneuronas inhibitorias. ${ }^{24}$

Mediante el estudio de la actividad sináptica de ambos tipos neuronales (interneuronas y neuronas dopaminérgicas) se observó que la activación del receptor $\alpha 1$ de las interneuronas produce potenciales postsinápticos inhibitorios miniatura (mIPSP) de mayor amplitud que los generados por la activación de los receptores $\alpha 3$ de las neuronas dopaminérgicas en presencia de BZD. De estos resultados se concluye que aunque ambos tipos neuronales son susceptibles al efecto de las BZD, las interneuronas lo son más, dejando de liberar GABA a las neuronas dopaminérgicas. Esto da como resultado una pérdida de la inhibición de estas últimas neuronas lo que promueve que la entrada excitatoria de las neuronas dopaminérgicas del AVT no tenga ningún contrapeso sináptico, lo que en última instancia termina produciendo la liberación descontrolada de DA en el NAC. ${ }^{24}$

Para corroborar que estos hallazgos electrofisiológicos tienen un correlato conductual, fue muy importante el uso de ratones transgénicos en los cuales se indujo la expresión de formas mutantes de la subunidad $\alpha 1$ del canal $\mathrm{GABA}_{\mathrm{A}^{\prime}}$ donde la histidina del sitio de unión a las BZD era substituida por una arginina, lo que deja al receptor insensible a las BZD. En estos experimentos los ratones fueron condicionados a tomar agua adicionada con azúcar, a la que posteriormente se le agregó midazolam. En estas condiciones, los animales silvestres (que no eran mutantes de la subunidad $\alpha 1$ ) incrementaron de manera significativa el consumo del agua adicionada con la BZD con respecto al promedio basal (previo al fármaco), mientras que los animales mutantes de la subunidad $\alpha 1$ (H101R) mantuvieron un consumo promedio con la BZD, de manera similar a cuando el agua no contenía el fármaco. De estos resultados se concluye que efectivamente la subunidad $\alpha 1$ del receptor $\mathrm{GABA}_{\mathrm{A}}$ media el efecto adverso de la dependencia física a las BZD, y que hay un correlato funcionalconductual entre la desinhibición del circuito AVT-NAC y la conducta de consumo compulsivo de la droga. ${ }^{24}$ 
Sin duda estos descubrimientos permitirán diseñar nuevas BZD que posean un menor riesgo de provocar dependencia en los pacientes, proporcionando así tratamientos más seguros y que mejoren su calidad de vida. Por ejemplo, del conocimiento obtenido por medio del estudio de modelos animales se deduce que un ansiolítico casi ideal sería una BZD agonista específico de la subunidad $\alpha 2$, que sin dejar de producir el efecto ansiolítico careciera del efecto secundario de la sedación y la amnesia. Sería por ello, sin duda, menos adictivo. La búsqueda de medicamentos con la posibilidad de producir en las personas los menores efectos secundarios graves, es unos de los retos más ambiciosos de la medicina contemporánea.

\section{AGRADECIMIENTOS}

Los autores desean agradecer a la doctora Angélica Almanza por la lectura crítica y la edición de este manuscrito.

\section{REFERENCIAS}

1. Ross JB. Fármacos y tratamientos para trastornos psiquiátricos. En: Hardman JG, Limbird LE, Molinoff PB, Ruddon RW, Goodman Gilman A (eds). Goodman y Gilman. Las bases farmacológicas de la terapéutica. Novena edición. México DF: McGraw Hill Interamericana; 1996.

2. Lalive AL, Rudolph $\mathrm{U}$, Luscher C, Tan KR. Is there a way to curb benzodiazepine addiction? Swiss Med Wkly 2011;141:w13277.

3. Micó JA, Rojas O, Gibert RJ. Benzodiacepinas y drogodependencias. Procedente de IV Encuentro Nacional y su Enfoque Comunitario, Encuentro de Profesionales en drogodependencia. Chiclana, España, 1997.

4. Medicamentos: Uso racional de los medicamentos [Internet]. Organización Mundial de la Salud. Mayo 2010 [Citado 2012 Marzo 3]. Disponible en: URL: http://www.who.int/mediacentre/factsheets/fs338/es/ index.html

5. Minaya $\mathrm{O}$, Ugalde $\mathrm{O}$, Fresán $\mathrm{A}$. Uso inapropiado de fármacos de prescripción: dependencia a benzodiazepinas en adultos mayores. Salud Mental 2009;32:405-411.

6. Fresán A, Minaya O, Cortés López JL, Ugalde O. Características demográficas y clínicas asociadas a la dependencia a benzodiacepinas en pacientes psiquiátricos. Salud Mental 2011; 34:103-109.

7. Ayuso Gutiérrez JL. ¿Está justificado el tratamiento prolongado con benzodiacepinas? Salud Mental 2008;31:429-430.

8. Torrens M. Dependencia de benzodiazepinas: Clínica y tratamiento [Internet]. Biblioteca virtual en adicciones [Citado 2012, May 15]. Disponible en: URL: http://www.biblioteca.cij.gob.mx/Archivos/Materiales_de_consulta/Benzodiazepinas/Articulos/Dependencia_de_benzodiacepinas.pdf
9. Caldentey CV, Arroyo LA. ¿Utilizamos adecuadamente las benzodiacepinas? El comprimido 2011;(21):2-7.

10. Busto UE. Factores de riesgo en el abuso y la dependencia a benzodiacepinas. Trastornos Adictivos 2000;2(3):177-182.

11. Wilson C, Yonette T, Kevin C, James C. Avances en la epidemiología del consumo de sustancias y de los trastornos por consumo de sustancias. Am J Psychiatry 2005;162:1494-1502.

12. Gervasini G, Carillo JA, Benitez J. Importancia del citocromo P-450 en terapéutica farmacológica. Monografía no. 14. En: Cascales M, GómezLechón MJ (ed). Citocromo P-450. Madrid: Instituto de España, Real Academia de Farmacia; 2004; pp. 387-418.

13. Barberá T, Avellana JA, Moreno L. ¿Se hace un buen uso de las benzodiacepinas en el anciano? Rev Clin Esp 2007;207(3):138-140.

14. Johnell K, Fastbom J. Gender and use of hypnotics or sedatives in old age: a nation-wide register-based study. Int J Clin Pharm 2011;33(5):788793.

15. Babilonis S, Lile J, Martin C, Kelly T. Physiological doses of progesterone potentiate the effects of triazolam in healthy, premenopausal women. Psychopharmacol 2001;215(3):429-439.

16. Guardia J, Surkov SI, Cardus M. Bases neurobiológicas de la adicción. En: Bobes J, Casas M, Gutiérrez M (eds). Manual de trastornos adictivos. Segunda edición. España: Enfoque Editorial, S.C; 2001.

17. JR Laporte JrX, Carné X. Metodología epidemiológica básica en farmacovigilancia. En: Laporte JR, Tognoni G (eds). Principios de epidemiología del medicamento. Segunda edición. Barcelona: Ediciones Científico-Técnicas; 1993.

18. Corominas M, Roncero C, Bruguera E, Casas M. Sistema dopaminérgico y adicciones. Rev Neurol 2007;44:23-31.

19. Lorenzo P, Moreno A, Leza JC, Lizasoain I et al. Farmacología básica y clínica. 17 ${ }^{\mathrm{a}}$ edición. Madrid: Editorial Medica Panamericana; 2005.

20. Rudolph U. Benzodiazepines. En: Offermanns S, Rosenthal W (eds). Encyclopedia of molecular pharmacology. Segunda edición. Nueva York: Springer-Verlag Berlin Heidelberg; 2008.

21. Ator NA. Contributions of GABAA receptor subtype selectivity to abuse liability and dependence potential of pharmacological treatments for anxiety and sleep disorders. CNS Spectr 2005;10(1):31-39.

22. Milenkovic I, Smalla KH, Gundelfinger ED, Kaehne T et al. The cell adhesion molecule neuroplastin-65 is a novel interaction partner of $\gamma$-Aminobutyric acid type A receptors. J Biol Chem 2012;287(17):1420114214.

23. Florence C, Karin L, Ruth K, Marie JM et al. Molecular targets for the myorelaxant action of diazepam. Mol Pharmacol 2001:59:442-445.

24. Kelly RT, Matthew B, Gwenaël L, Cédric $Y$ et al. Neural bases for addictive properties of benzodiazepines. Nature 2010:463(7282):769774.

25. Fernández E. Bases neurobiológicas de la drogadicción. Rev Neurol 2002;34:659-664.

26. Mercado F, Almanza A. Adicción a las benzodiacepinas: bases neuronales. Elementos: Ciencia Cultura 2010;17:57-58.

27. Kelly RT, Rudolph U, Christian L. Hooked on benzodiazepines: GABAA receptor subtypes and addiction. Trends Neurosciences 2011;34(4):188-197.

28. Micó J, Moreno M, Roca A, Rojas M et al. Neurobiología de la adicción a nicotina. Prev Tab 2000;2(2):101-105.

Artículo sin conflicto de intereses 